It will be seen that there is a remarkable degree of resemblance in the progression of these phenomena from year to year, but that the barometric curve "lags behind" the sun-spot curve, particularly in the years of maximum sun.spots.

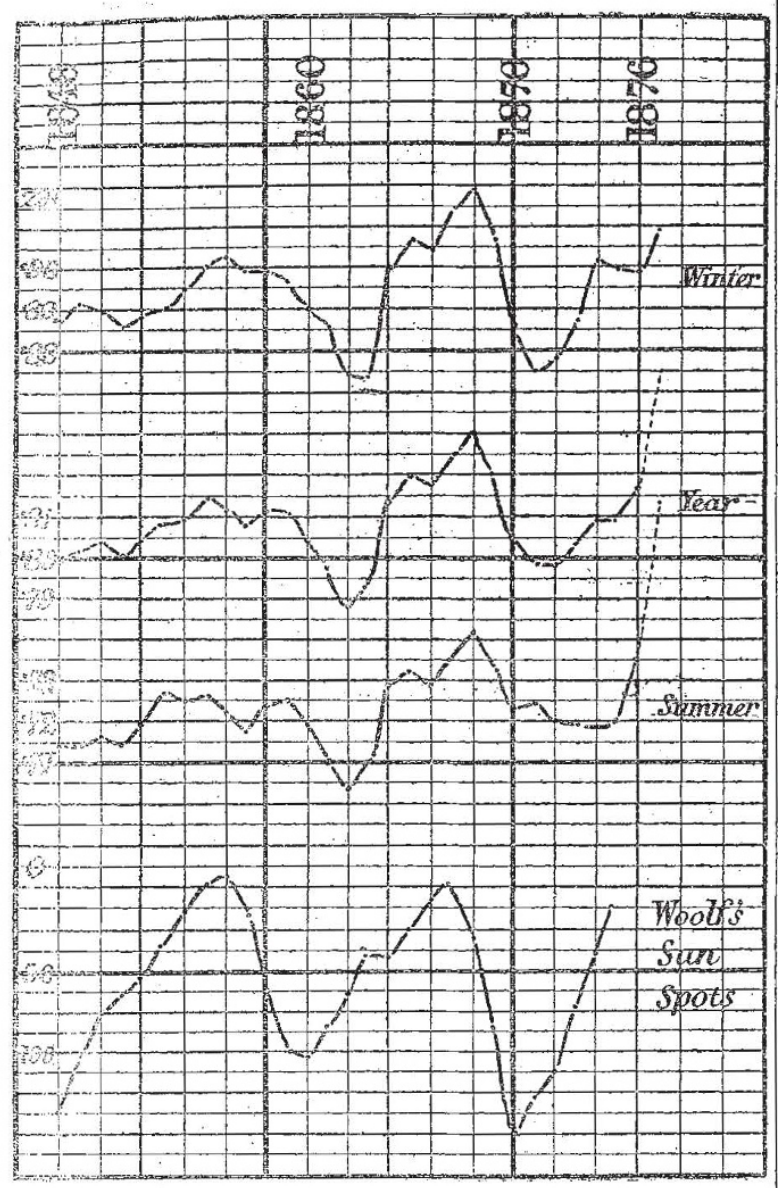

The winter curve is more regular than the "summer one, probubly because the weather generally in India is more settled in the winter than in the summer, but on the whole the two curves support each other in showing a low pressure about the time of sun-spot maximum, and a high pressure at the time of sum-spot minimum. We may therefore conclude that the sun is hoitust about the time when the spots are at a maximum, and coldest when they are at a minimum.

The range of the variation of the year by mean pressure from the minimum of 1862 to the maximum of 1868 , is 042 of an inch, and the mean range of the barometer from January to July is $29 \mathrm{I}$, from which it appears that the variations of pressure produced by absolnte variations of the sun's heat are, in comparison with the usual seasonal changes, by no means insignificant.

These results appear to harmonise well with the decennial variations of the rainfall in India, and to throw light upon the inverse variation (compared with the sun-sjots) of the winter rainfall of Northern India. Mr. Archibald has attempted to explain this latter phenomenon on the assumption that the sun is coldest when it is most spotted, but the inverse winter variation of the rainfall of Northern India, as well as the direct variation at Madras, Bombay, Trevandrum, and elsewhere, appear to me to follow more naturally from the contrary view; for if the winter rainfall in Northern India is really due to the cold of winter we should expect it to be greatest when the sun is colciest, just as the summer rainfall is expected to be greatest when the sun is hottest.

Bombay, August 23:
The Norwegian Arctic Expedition

THE Vöringen, Capt. Wille, returned to Christiania on the roth, from Spitzbergen, after a most successful cruise. No less than 375 stations have been thus explored by sounding, dredging, and trawling during the last three summers; and the Morgenbladet reminds us that only 354 of such stations were recorded in the notice of the Challenger expedition. The number of stations in the Porcupine cruises of 1869 and 1870 was 148 .

Prof. G. O. Sars informs me that in every department of zoology a vast amount of material was procured in his last cruise, and that especially the Mollusca are abundantly represented, not only by magnificent specimens of rare Arctic species, such as Fusus kroyiri and $F$. (Neptunea) deformis, but also by several interesting new forms. He adds that the conchological collection from this cruise is indeed much richer than both of those made in his former two cruises. Herr Friele will work out all the Mollusca.

I cannot omit expressing my admiration of the recent work of Prof. G. O. Sars, entitled "Mollusca Regionis Arcticæ Norvegize." His descriptions are excellent, and his figures (all by his own hand, and autographed) are inimitable. The work contains 466 pages and 52 plates, besides a chart.

Ware Priory, Herts, September 23 J. Givyn Jefrreys

\section{Albinism in Birds}

WHEN I was forming the Government Central Museum at Madras, an albino crow was brought to me, which was stuffed and placed in the museum. It was mentioned to me at the same time that there is a colony of albino crows at a part of the Malabar coast, but I have never been able to verify the statement. That district is daily becoming more frequented by Europeans, and some of them may soon be in a position to ascertain how far the report was correct. EDWARD BALFOUR

2, Oxford Square, September 19

As Mr. Page says, in NAtuRE (vol. xviii. p. 540), he has only heard of one white swallow, it may be interesting to him and your readers to learn that in the Newcastle Musem there is a specimen, also white specimens of the rook, pheasant, curlew, sparrow, and starling; in the same collection will also be found a "pale rose" coloured specimen of the bullfinch.

Newcastle-upon-Tyne, September 20

WM. LYALI

\section{"Hearing of Insects"}

I AM able to confirm the accounts given by Mr. Simson in your last number as to the probability of the hearing of insects. When travelling on the River Magdalena, New Granada, in 186I, the mode of which is by a long boat, arched over with bamboo, on which the sailors (bogas) passing from one extremity to the other, propel it with long poles, hugging the river bank, accompanied with wild cries and execrations, I observed on several occasions that these cries suddenly ceased, a dead silence following, and on inquiring the cause they pointed to nests high up in the trees, whispering the word vispa (wasp). As the bogas pursue their avocations in a state of semi-nudity, they have the greatest dread of these insects, fearing to speak aloud, as their only alternative if attacked by them is to plinge into the stream, where alligators abound. The wasp is long; slencer, and black in colour.

II7, Cromwell Road, S.W., Sept. 2r

W. L. DudLey

\section{The Meteor Shower of Andromedes I.}

Mr. GREG'S meteor radiant (No. I03 of his 1876 catalogue) at R.A. $7^{\circ}$, Dec. $33^{\circ}$ N., for July: 21 to August, really consists of two well-defined showers near a Andromeda. The meteors are quite distinct, and, moreover, there is a difference of $10^{\circ}$ in declination. My observations since 1873 indicate two positions as below :-

I. July 6 to August $16,6^{\circ}+37^{\circ}\{60$ very swift streal-leaving II. July 6 to August II, $3^{\circ}+27^{\circ}\{23$ slow, bright, trained

Schiaparelli and Zezioli, Greg and Herschel, and Tupman, found the former some years ago, and Denza gives the latter at $2^{\circ}+29^{\circ}$ August $8-13$. Mr. Greg averages these with several others (including one by Schmidt at $7^{\circ}+30^{\circ}$, and another by Heis at $11^{\circ}+30^{\circ}$, both for August) and finds a centre at $7^{\circ}+33^{\circ}$ for the whole. There is no doubt, however, that there are two conspicuous contemporary radiants of entirely 